Strabismus 0927-3972/99/US\$ I 5.00

Strabismus - I999, Vol. 7, No. 3, p. 145

(C) Atus Press 1999

\section{Translation of 'The movements of the human eye' by F.C. Donders}

In this issue of Strabismus, you will find a translation of the original description of Donders' law. Donders noticed that afterimages tilted when he looked left and right with his chin up, or tilted the other way when looking left and right with his chin down. The tilt, now known as pseudotorsion, is a mathematical side-effect and occurs because the eye has to comply with Listing's law.

As you read the article, you will notice that Alexander Hueck was condemned heavily by Donders for his description of ocular counterrolling in I838. It took another 20 years before Javal rediscovered ocular counterrolling in I866 and Alexander Hueck was rehabilitated.

H.J. Simonsz 